\title{
DEMONSTRATING ADEQUATE SAFETY FOR A CONCRETE COLUMN EXPOSED TO FIRE, USING PROBABILISTIC METHODS
}

\author{
Ruben Van Coile, Ghent University, Belgium \\ Danny Hopkin, OFR Consultants \& The University of Sheffield, UK \\ Negar Elhami Khorasani, University at Buffalo, USA \\ Thomas Gernay, Johns Hopkins University, USA
}

\begin{abstract}
Demonstrating adequate safety for exceptional designs and new design applications requires an explicit evaluation of the safety level, considering the uncertainties associated with the design. The recently published PD 7974-7:2019 provides five routes to demonstrating adequate safety through probabilistic methods but does not include worked examples. The case study in this paper presents three state-of-the-art approaches for demonstrating achievement of an absolute safety target (acceptance concept 'AC3' in PD 7974-7:2019) for a concrete column in an office building with stringent reliability requirements. The case study shows how fragility curves listed by, for example, industry organizations can support probabilistic approaches and a more comprehensive understanding of design performance.
\end{abstract}

\section{INTRODUCTION}

For common applications, the combination of prescriptive fire resistance requirements on the one hand, and tabulated design solutions and standardized calculation methods on the other hand, provides an efficient and practical means for demonstrating adequate fire resistance. For exceptional designs and new design applications, however, the attainment of adequate structural fire safety must be based on an explicit evaluation of the safety level ${ }^{1}$. This entails due consideration of the uncertainties associated with the design, and implies demonstrating that the residual risk incorporated in the structural fire design is both tolerable and As Low as Reasonably Practicable (ALARP). Incorporating the above, the revised British guidance document on Probabilistic Risk Assessment for Fire Engineering, PD 79747:2019² provides five routes to demonstrating adequate safety and design acceptance. PD 7974-7:2019 however does not include worked examples.

In the following, an application is presented for a fire-exposed concrete column in a reference building. The reference building is taken from Eurocode 2 guidance documents ${ }^{3}$, where the application of prescriptive design rules are presented, and has been the basis for the performance based structural fire engineering example in the ISO Technical Report ISO/TR 24679-6:2017 ${ }^{4}$. Comparison of the analysis presented further with the above two reference documents illustrates how different design methodologies can be applied to the same building.

\section{DEMONSTRATING ADEQUATE SAFETY IN ACCORDANCE WITH PD 7974-7:2019}

The recently published PD 7974-7:2019² provides guidance on the application of probabilistic risk assessment (PRA) methodologies to fire engineering projects. In accordance with PD 7974-7:2019, demonstrating adequate safety for a given fire safety objective entails (at least conceptually) a two-step approach. Firstly, the tolerability of the design is to be demonstrated, considering the full spectrum of potential consequences and their associated occurrence frequencies. The tolerability evaluation excludes the realization of designs which entail damage frequency/severity combinations which are unacceptable to the stakeholders ${ }^{1}$ (incl. society at large), and is commonly represented by a limiting curve in a 2D frequency-consequence visualization (Figure 1). In the field of life safety, this type of 
diagram is commonly denoted as an "FN-diagram". Without violating the concept of the 2D tolerability limit, it is possible to specify tolerability limits only as maximum tolerated damage (a vertical line in the diagram), or maximum frequency of damage (a horizontal line), a combination of both, or neither.

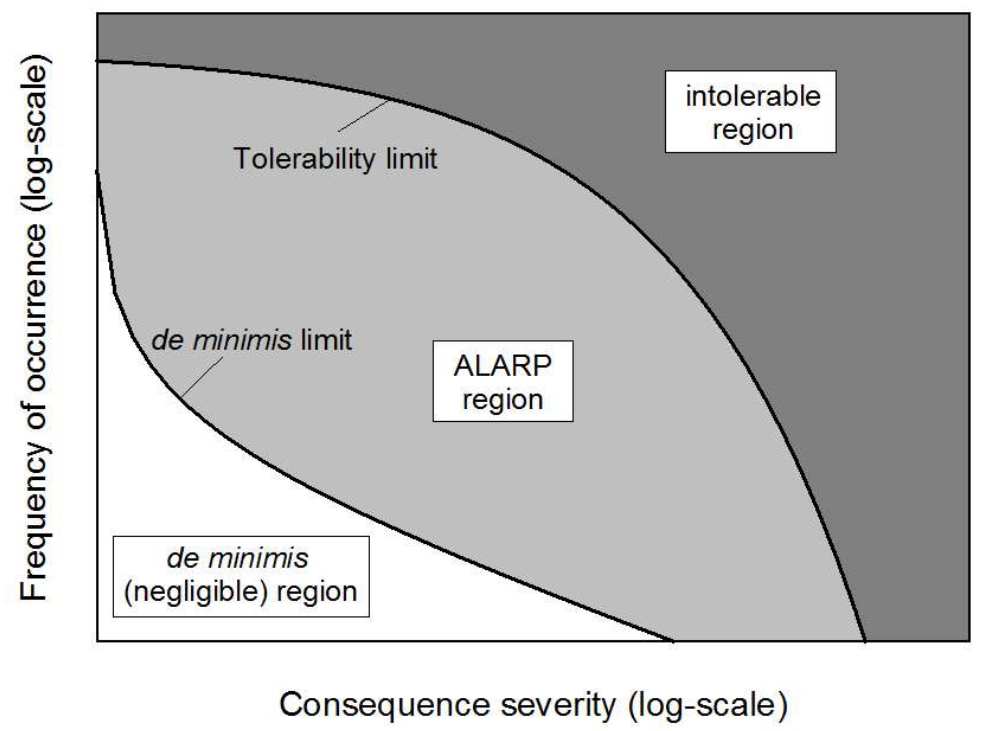

Figure 1. Frequency-consequence (FC) diagram indicating the tolerability limit and ALARP region ${ }^{1}$.

Having demonstrated tolerability of the design, acceptance of the design relies on demonstrating that the residual risk is ALARP (i.e. As Low as Reasonably Practicable), or that the risk profile is thus so low that the design falls in the de minimis or broadly acceptable region where no further investigations are required. Demonstrating ALARP can be done ${ }^{2}$ (Figure 2) (i) directly, by a cost-benefit analysis (AC4); (ii) indirectly, by demonstrating equivalent safety to a design which is deemed ALARP (AC5); (iii) indirectly, by demonstrating a failure probability below a specified threshold (AC3). As a costbenefit analysis can be demanding and introduces non-trivial questions of consequence valuation, the approximate methods can be considered more practical. These approximate methods however heighten the onus put on the fire safety engineer, as the engineer is responsible for ensuring that the approximation is conservative (i.e. the final safety level is at least as high as when applying an explicit cost-benefit analysis).

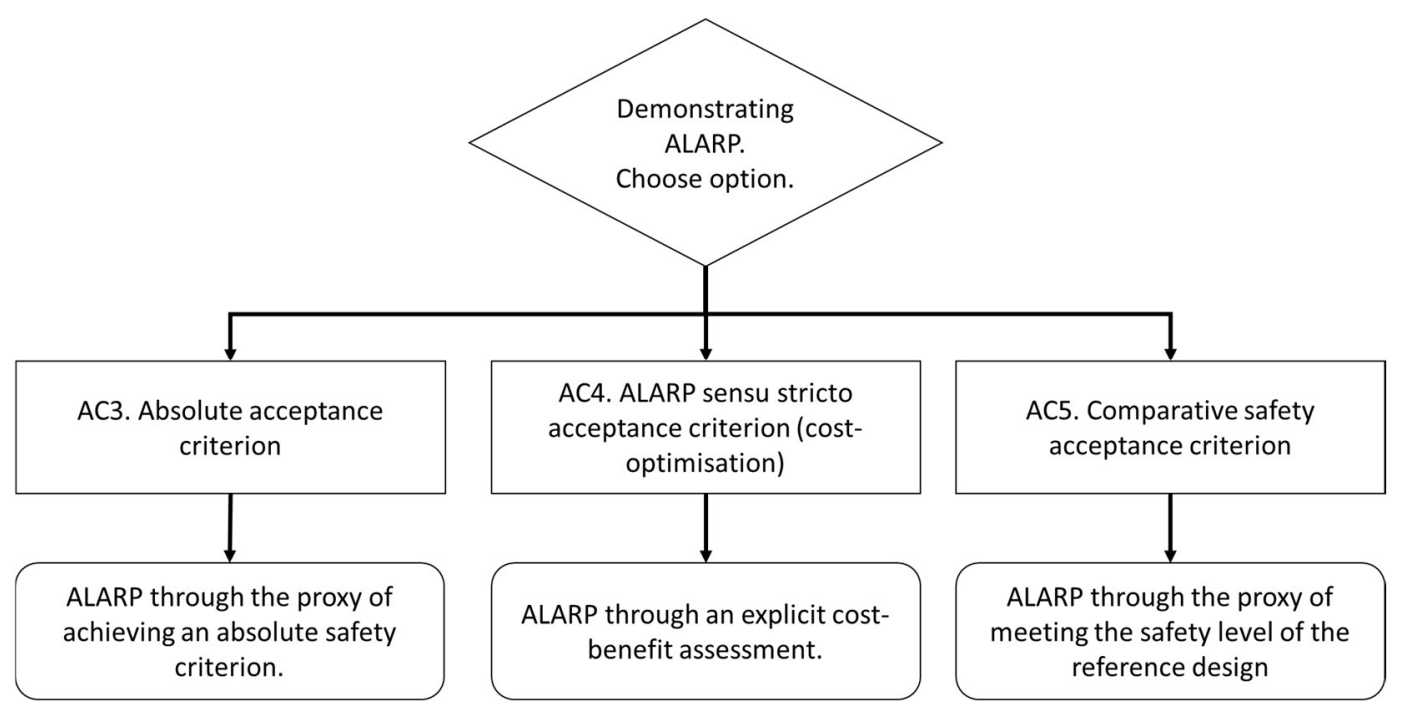

Figure 2. Routes to demonstrating ALARP5 ${ }^{5}$ AC3-5 is terminology applied in PD 7974-7:2019². 


\section{ADEQUATE SAFETY EVALUATION FOR A FIRE-EXPOSED CONCRETE COLUMN}

\subsection{Introduction}

Whereas PD 7974-7:2019 speaks in general terms on demonstrating adequate safety, it does not include worked examples. In the following the 'AC3' acceptance criterion of an absolute safety target is applied to demonstrate adequate safety for a fire-exposed concrete column. As discussed further, the absolute safety target is in hypothesis set through stakeholder discussions. Whereas prescriptive guidance does not provide the stakeholders with insight into the expected performance of the structure, the explicit definition of a safety target stimulates clear communication of expectations. Where the example below mentions stakeholder communication, this is hypothetical and has been introduced for reference.

In the following, the steps listed in ISO 24679-1:2019 in the performance-based assessment of structures exposed to fire are applied to give a full overview of how the probabilistic methods can be incorporated into the overall design assessment. The terminology applied, e.g. functional requirement, is considered in accordance with this International Standard and may differ from national guidance.

If no prior information on the probabilistic characteristics of the investigated concrete elements is available, technically advanced procedures must be applied which can be computationally expensive. If reliable information is available in scientific literature or in guidance documents published by standardization bodies, industry organizations or manufacturers, alternative straightforward and efficient probabilistic assessments are possible. In 3.7 (step 7: assessment against the fire safety objectives), three of these alternative approaches are illustrated.

\subsection{Step 1: Scope}

The reference concrete building by Biasoli et al. ${ }^{3}$ is considered, as applied in ISO/TR 24679-6:20174. The building is an open-plan office building, with plan visualized in Figure 3. The concrete columns are $500 \times 500 \mathrm{~mm}^{2}, \mathrm{C} 30 / 37$ with siliceous aggregates, reinforced with 12 longitudinal rebars of diameter $20 \mathrm{~mm}$ with $42 \mathrm{~mm}$ of concrete cover. The ground floor columns have a height of $4 \mathrm{~m}$.

Considering load transfer calculations reported in ISO/TR 24679-6:2017 and a load ratio $\chi=Q_{k} /\left(G_{k}\right.$ $+Q_{k}$ ) of approximately 0.40 , the most loaded concrete column is subjected to axial forces with $P_{G k}=$ $2000 \mathrm{kN}$ for the permanent load effect (characteristic value), and $P_{Q k}=1333 \mathrm{kN}$ for the imposed load effect (characteristic value).

The office building is eight stories tall. As a 'common' building it falls within the scope of prescriptive guidance. Tolerability of the design is assumed as ensured by its design in accordance with prescriptive guidance.

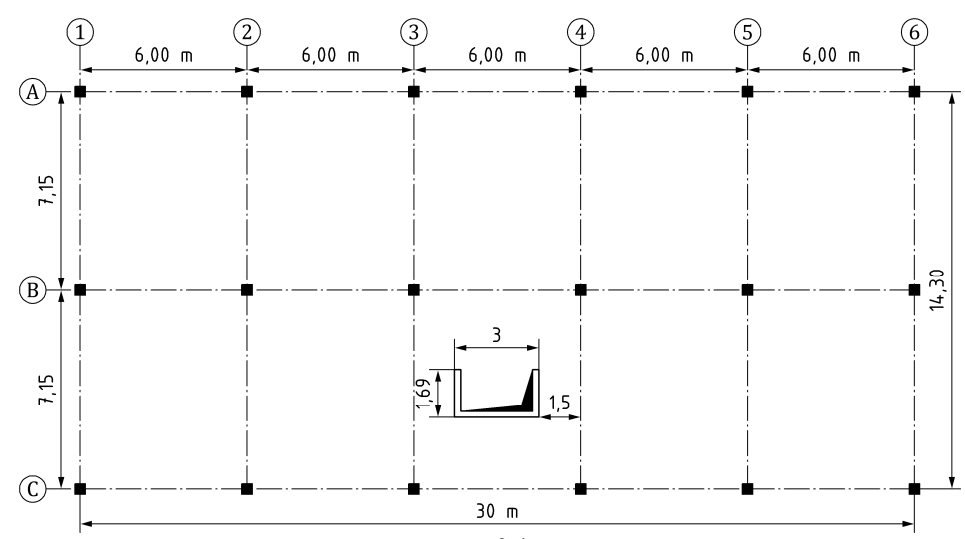

Figure 3. Plan of the building ${ }^{3,4}$ and column cross-section. 


\subsection{Step 2: Identifying objectives, functional requirements and performance criteria}

The objectives for structural fire safety are considered in agreement with ISO/TR 24679-6:2017: (i) life safety of the occupants and fire fighters (incl. search and rescue); (ii) conservation of property; and (iii) continuity of operations. Taking into account the crucial function of the ground-floor columns for the overall stability, and acknowledging the ISO 834 standard fire (or rather: standard heating regime) as a common point of reference, the functional requirement is specified as (in hypothesis taking into account stakeholder consultation): no loss of stability for the most loaded ground floor column considering 240 minutes of ISO 834 standard fire exposure. While the ISO 834 standard fire is most useful for stakeholder communication, it must be emphasized that an evaluation with respect to this fire can only serve as a proxy for a direct assessment of post-fire performance and reparability. Notably, a modelling of cooling-phase behaviour is in this regards crucial to obtain a realistic post-fire assessment, see Gernay $^{7}$.

Imperfections in the column geometry and stochastic variations in the concrete compressive strength and reinforcement yield stress imply uncertainty with respect to the column performance. This infers that a prescriptive design solution would have an unknown probability of not achieving the functional requirement. Ensuring a high reliability of achieving the functional requirement, the performance criterion selected to fulfil the above objectives and functional requirements is (in hypothesis taking into account stakeholder consultation): structural stability of the most loaded ground floor column considering 240 minutes of ISO 834 standard fire, is to be maintained with a reliability $P_{s, f i}$ of $99.5 \%$. This corresponds with a probability of failure given fire exposure of no more than $0.5 \%\left(P_{f, f i} \leq 5 \cdot 10^{-3}\right)$. These limits are commonly denoted as the target reliability $P_{s, f i, t}$ and target failure probability $P_{f, f, i, t}$.

The reliability target specified above, taking into account 240 minutes standard fire exposure, can be considered as very stringent. The stringent requirement on the one hand compensates for neglected effects such as cooling behaviour, and on the other hand relates to very high reliability requirements specified (in assumption) through stakeholder discussion. Importantly, these values should not be interpreted as a general recommendation and serve as an example for application purposes herein.

\subsection{Step 3: Trial plan; and Step 4: Design fire scenario}

The building design plan is a given, as specified in 3.2, and the design fire scenario is specified as part of the considered functional requirement. The standard fire exposure is considered to aggregate all possible design fire scenarios into a single conventional design fire for ease of communication. In other words, achieving the performance requirement of stability for the most loaded column with $99.5 \%$ reliability for this severe conventional fire exposure is (in assumed stakeholder consultation) deemed to ensure the structural performance when exposed to any (reasonably possible) real fire development. This is a significant idealization, but reflects common practice for straightforward buildings designed on the basis of prescriptive guidance as a common point of reference for all parties involved.

\subsection{Step 5: Thermal response}

The thermal response of the concrete column is evaluated considering EN 1992-1-2:2004 ${ }^{8}$, taking into account an average thermal conductivity, and a water content of $2 \%$ of mass. The temperature response was calculated using the dedicated finite element software SAFIR ${ }^{9}$.

\subsection{Step 6: Mechanical response}

The most-loaded concrete column is modelled in SAFIR ${ }^{9}$. The $4 \mathrm{~m}$ long column is modelled in 2D using 10 beam elements with a pinned support at the bottom and a roller support at the top. These boundary conditions neglect the rotational restraint, which results in a more onerous evaluation for the column, as its effective length is overestimated, but allows to model the column in isolation. Also possible differences in longitudinal expansion of the ground floor columns and stair-core are not considered, neglecting resulting axial restraint effects. 
As listed in ISO TR 24679-6:2017 $7^{4}$, the structural fire analysis considers the following assumptions: (i) plane sections remain plane (Bernoulli hypothesis); (ii) effects of non-uniform temperature distribution in the section considered through a fiber model; (iii) shear energy of the plane sections ignored; (iv) uniaxial constitutive models; (v) large displacements are considered but strains are assumed small. For given realization of the column characteristics (concrete compressive strength, steel yield stress, column geometry) and axial load $\mathrm{P}$, the deformation of the column and the time of structural failure are evaluated, see example result in Figure 4. This evaluation is done considering a resolution of 1 minute.

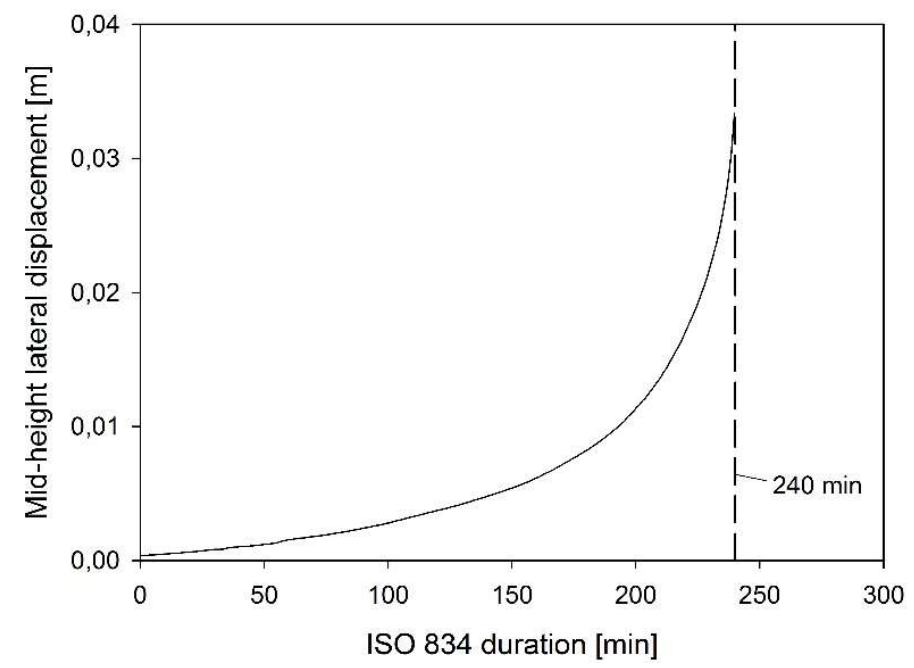

Figure 4. Example mid-height lateral deflection of a column in function of the ISO 834 standard fire duration, and indication of assessed time of structural failure.

\subsection{Step 7: Assessment against the fire safety objectives}

\section{General}

The performance criterion requires that the column has a $99.5 \%$ reliability of maintaining structural stability up to 240 minutes of exposure to the ISO 834 standard fire. The achieved reliability is evaluated considering the uncertainties associated with the characteristics defining the column. The considered stochastic parameters and their probabilistic models are listed in Table 1. The meaning of the parameters eccentricity, out of straightness and out of plumbness are illustrated in Figure 5, as listed in the JCSS Probabilistic Model Code ${ }^{10}$. The concrete cover and concrete compressive strength retention factors have been considered deterministically through their nominal values. The nominal value of the concrete compressive strength retention factor is taken as specified in EN 1992-1-2:2004 ${ }^{8}$. Recent research has investigated the probabilistic description of the concrete compressive strength retention factor, see Qureshi et al. ${ }^{11}$, and will be included in follow up evaluations.

Table 1. Probabilistic description of parameters concrete column

\begin{tabular}{|c|c|c|c|c|}
\hline Parameter & Distribution & Mean $\mu$ & $\begin{array}{l}\text { Standard } \\
\text { deviation } \sigma\end{array}$ & Reference \\
\hline $\begin{array}{l}20^{\circ} \mathrm{C} \text { concrete compressive } \\
\text { strength, } f_{c 20}[\mathrm{MPa}]\end{array}$ & Lognormal & $\begin{array}{c}42.9 \\
\left(f_{c k}=30 \mathrm{MPa}\right)\end{array}$ & 6.4 & $\begin{array}{l}\text { Holický and } \\
\text { Sýkora }^{12}\end{array}$ \\
\hline $\begin{array}{l}20^{\circ} \mathrm{C} \text { reinforcement yield stress, } \\
f_{y, 20}[\mathrm{MPa}]\end{array}$ & Lognormal & $\begin{array}{c}560 \\
\left(f_{y k}=500 \mathrm{MPa}\right)\end{array}$ & 30 & $\begin{array}{l}\text { Holický and } \\
\text { Sýkora }^{12}\end{array}$ \\
\hline $\begin{array}{l}\text { Steel yield stress retention factor } \\
\text { at elevated temperature, } k_{f y}[-]\end{array}$ & Logistic & $\begin{array}{l}\text { Temperature } \\
\text { dependent }^{13}\end{array}$ & $\begin{array}{l}\text { Temperature } \\
\text { dependent }^{13}\end{array}$ & $\begin{array}{l}\text { Khorasani et } \\
\text { al. }{ }^{13}\end{array}$ \\
\hline average eccentricity, $e[\mathrm{~m}]$ & Normal & 0 & 0.004 & $\mathrm{JCSS}^{10}$ \\
\hline out of straightness, $f[\mathrm{~m}]$ & Normal & 0 & 0.004 & $\mathrm{JCSS}^{10}$ \\
\hline out of plumbness, $\Phi[\mathrm{rad}]$ & Normal & 0 & 0.0015 & $\mathrm{JCSS}^{10}$ \\
\hline
\end{tabular}



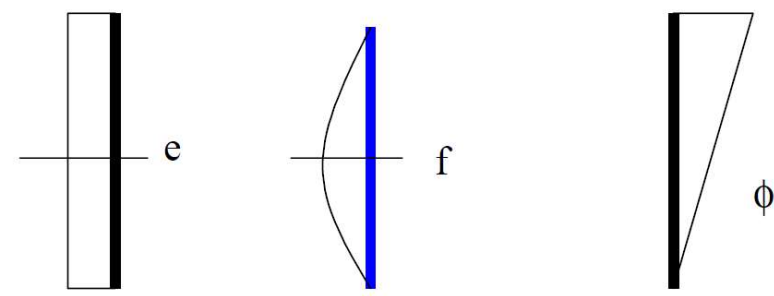

Figure 5. The three basic eccentricities: average eccentricity $e$, out of straightness $f$, and out of plumbness $\Phi$, as listed in the JCSS Probabilistic Model Code ${ }^{10}$

Not only the column characteristics exhibit uncertainty, but also the load effects $G$ and $Q$ which coincide with a (nominal) fire event. Furthermore, both the resistance effect $R$ of the column load bearing capacity and the load effect $E$ are associated with model uncertainties ( $K_{R}$ and $K_{E}$ respectively). The corresponding probabilistic models are listed in Table 2. For the permanent and imposed load effect, these models are considered to relate to the arbitrary point-in-time loads present in conjunction with fire exposure. The model uncertainty for the resistance effect is considered as a conservative evaluation based on expert judgement, considering ambient design model uncertainties.

Table 2. Probabilistic description of the load and model uncertainty

\begin{tabular}{|c|c|c|c|c|}
\hline Parameter & Distribution & Mean $\mu$ & $\begin{array}{c}\text { Standard } \\
\text { deviation } \sigma\end{array}$ & Reference \\
\hline Permanent load effect, $P_{G}[\mathrm{kN}]$ & Normal & $P_{G k}$ & $0.1 P_{G k}$ & $\begin{array}{l}\text { Holický and } \\
\text { Sýkora }^{12}\end{array}$ \\
\hline Imposed load effect, $P_{Q}[\mathrm{kN}]$ & $\begin{array}{c}\text { Gumbel } \\
\text { (5 year reference) }\end{array}$ & $0.2 P_{Q k}$ & $0.22 P_{Q k}$ & $\begin{array}{l}\text { Holický and } \\
\text { Sýkora }^{12}\end{array}$ \\
\hline $\begin{array}{l}\text { Model uncertainty for the load } \\
\text { effect, } K_{E}[-]\end{array}$ & Lognormal & 1.0 & 0.1 & $\begin{array}{l}\text { Holický and } \\
\text { Sýkora }^{12}\end{array}$ \\
\hline $\begin{array}{l}\text { Model uncertainty for the } \\
\text { resistance effect, } K_{R}[-]\end{array}$ & Lognormal & 1.0 & 0.15 & $\begin{array}{l}\text { Gernay et } \\
\text { al. }{ }^{14}\end{array}$ \\
\hline
\end{tabular}

The performance criterion of the column maintaining stability is associated with the limit state function of Equation (1), where $P_{\max }$ is the load bearing capacity of the column and $P_{E}$ is the total axial load. Considering the design fire specified above, $P_{\max }$ refers to the load bearing capacity at 240 minutes of ISO 834 standard fire exposure. The performance criterion is then given by Equation (2), with $P[$.$] the$ probability operator.

$$
\begin{aligned}
& Z=P_{\max }-P_{E} \geq 0 \\
& P_{s, f i}=P[Z>0]=P\left[P_{\max }-P_{E}>0\right] \geq P_{s, f i, t}=0.995
\end{aligned}
$$

The distribution of $P_{\max }$ can be evaluated considering the distributions of the input variables in Table 1 and Table 2. This can be done either through a direct calculation, or by applying a 'listed' fragility curve, after which the failure probability $(Z<0)$ can be evaluated. Alternatively, a semi-probabilistic approach can be used in case the type of distribution describing $P_{\max }$ is known. These alternative approaches are listed below.

\section{Assessment method 1: full probabilistic analysis - direct calculation of probabilities}

The performance criterion of Equation (2) can be evaluated directly, using reliability methods such as described by Ditlevsen and Madsen ${ }^{15}$. In order to do so, the probability distributions describing $P_{\max }$ and $P_{E}$ are assessed first. The reliability is then evaluated considering the left-hand equalities of Eq. (2).

The total load effect $P_{E}$ is evaluated directly through the distributions listed in Table 1 and Table 2 as 
$K_{E} \cdot\left(P_{G}+P_{Q}\right)$. The total load can be approximated by a lognormal distribution, with mean and standard deviation assessed by a Taylor approximation, i.e. Eqs. (3) and (4). For reference, the appropriateness of this approximation is illustrated in Figure 6. Considering (3) and (4), the coefficient of variation $V_{P E}$ is approximately 0.19 .

$$
\begin{aligned}
& \mu_{P_{E}}=\mu_{K_{E}}\left(\mu_{P_{G}}+\mu_{P_{Q}}\right)=2266.6 \mathrm{kN} \\
& \sigma_{P_{E}}=\sqrt{\sigma_{K_{E}}^{2}\left(\mu_{P_{G}}+\mu_{P_{Q}}\right)^{2}+\mu_{K_{E}}^{2}\left(\sigma_{P_{G}}^{2}+\sigma_{P_{Q}}^{2}\right)}=421.2 \mathrm{kN}
\end{aligned}
$$

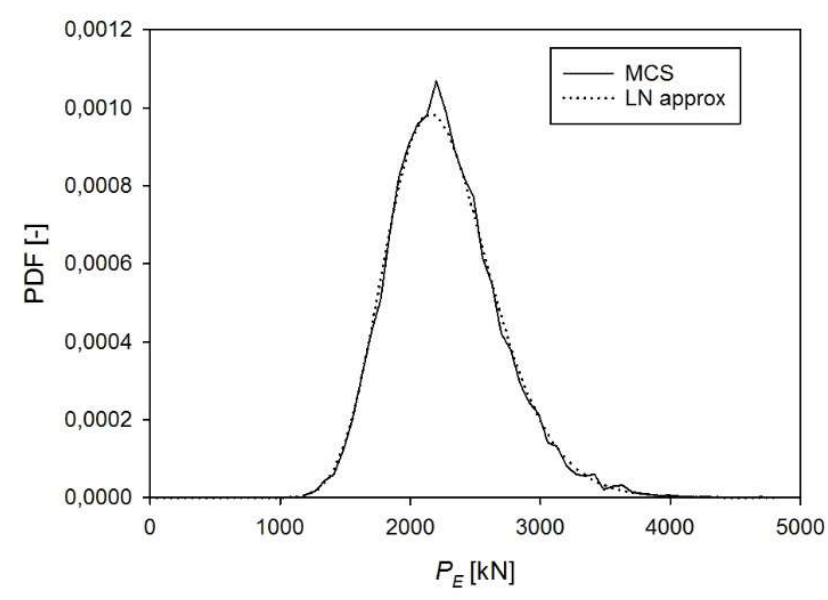

Figure 6. Total load effect $P_{E}$ : numerical evaluation and lognormal approximation

The column load bearing capacity $P_{\max }$ at 240 minutes ISO 834 exposure is evaluated by Equation (5), where $K_{R}$ is the model uncertainty listed in Table 2 and $P_{\max , \text { num }}$ is evaluated numerically, adopting SAFIR, by assessing the maximum load for which the run-off failure (as illustrated in Figure 4) does not occur prior to 240 minutes of standard fire exposure. The distribution of $P_{\max , \text { num }}$ is evaluated using Latin Hypercube Sampling ${ }^{16}$, taking into account the stochastic variables listed in Table 1. Results for $10^{4}$ realizations are visualized in Figure 7 (left hand: cumulative density function, CDF, and complementary cumulative density function, $\mathrm{cCDF}$; right hand: probability density function, $\mathrm{PDF}$ ), together with a lognormal approximation. The observed mean and standard deviation for $P_{\max , \text { num }}$ are listed further in Table 3. More computationally efficient, but approximate, methods exist for assessing the distribution of $P_{\max , \text { num }}$, e.g. Van Coile et al. ${ }^{17}$ as applied in Gernay et al. ${ }^{14}$.

$$
P_{\text {max }}=K_{R} P_{\text {max }, \text { num }}
$$
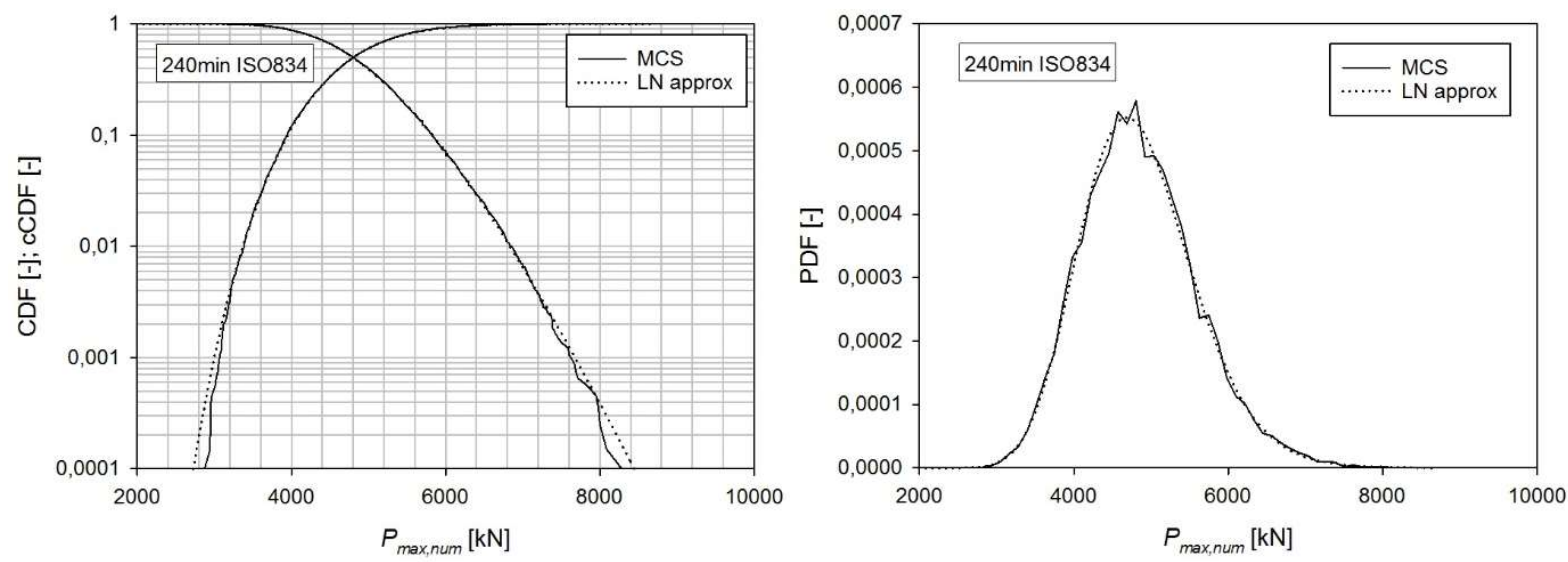

Figure 7. $P_{\max , \text { num }}$ : numerical evaluation and lognormal approximation. Left hand: cumulative density function $(\mathrm{CDF})$ and complementary cumulative density function (cCDF). Right hand: probability density function (PDF) 
As both $P_{\max }$ and $P_{E}$ are described by a lognormal distribution, $P_{f, f}$ is directly given by Equation (6), with $\Phi$ the standard normal cumulative distribution function. Evaluating (6), the probability of failure given the (standard) fire exposure is lower than the performance criterion of $P_{f, f i} \leq 5 \cdot 10^{-3}$. Equivalently, the reliability of the column is assessed to exceed $99.5 \%$ for the prescribed standard fire exposure duration. The design is accepted with respect to the structural fire safety objectives, in accordance with the performance criterion specified in Step 3.

Table 3. Distributions describing $P_{\max }$ (240 min ISO 834)

\begin{tabular}{|l|c|c|c|c|}
\hline Parameter & Distribution & Mean $\boldsymbol{\mu}$ & $\begin{array}{c}\text { Standard } \\
\text { deviation } \boldsymbol{\sigma}\end{array}$ & $\begin{array}{c}\text { Coefficient of } \\
\text { variation V }\end{array}$ \\
\hline $\begin{array}{l}\text { Numerical evaluation of the } \\
\text { maximum load, } P_{\max , \text { num }}[\mathrm{kN}]\end{array}$ & Lognormal & 4854.1 & 742.5 & 0.15 \\
\hline $\begin{array}{l}\text { Model uncertainty for the } \\
\text { resistance effect, } K_{R}[-] \text { (Table 2) }\end{array}$ & Lognormal & 1.0 & 0.15 & 0.15 \\
\hline $\begin{array}{l}\text { Column load bearing capacity, } \\
P_{\max }[\mathrm{kN}]\end{array}$ & Lognormal & 4854.1 & 1045.9 & 0.22 \\
\hline
\end{tabular}

$$
P_{f, f i}=\Phi\left(\frac{\ln \left(\frac{\mu_{P_{E}}}{\mu_{P_{\max }}}\right) \sqrt{\frac{V_{P_{\max }}^{2}+1}{V_{P_{E}}^{2}+1}}}{\sqrt{\ln \left(\left(V_{P_{\max }^{2}}^{2}+1\right)\left(V_{P_{E}}^{2}+1\right)\right)}}\right)=3.6 \cdot 10^{-3}
$$

\section{Assessment method 2: full probabilistic analysis - evaluation through listed fragility curve}

The direct calculation of probabilities above relied on the application of methods of reliability analysis, such as Latin Hypercube Sampling. This evaluation required both (i) the development of a numerical model; and (ii) repeated random sampling of the model. This may reasonably limit direct probability calculations to specific projects and code-calibration purposes, which warrant the associated efforts and computational expense. Probabilistic methods however have a much wider potential, especially considering their ability to elucidate the expected performance of the structure through measures of confidence. Therefore, it is suggested that to allow for fast (approximate) reliability evaluations, researchers, industry organizations and standardization bodies can list fragility curves for fire-exposed structural elements. It is envisaged that the usage of listed fragility curves can allow for the wider application of probabilistic methods in design, as is the case for earthquake engineering. Recent literature studies have already demonstrated considerable interest in the development of fragility curves, see e.g. Gernay et al. ${ }^{18}$, Rush et al. ${ }^{19}$ and Hopkin et al. ${ }^{20}$. Listed fragility curves (i.e. distributions) allow for the fast and easy application of dedicated reliability software, such as COMREL ${ }^{21}$, limiting computational cost.

In the following, $P_{\max }$ has been (in hypothesis) listed for the given standard fire exposure and column design in literature, by a manufacturer or industry organization. The fragility curve is visualized in Figure 8, together with its specification as a lognormal distribution. This specification corresponds with the result obtained through computationally expensive simulation in Table 3, after rounding.

Taking into account the model for the load effect specified above as $K_{E} \cdot\left(P_{G}+P_{Q}\right)$ and the load parameters in Table 2, the limit state function for the column is given by Eq. (7). The distributions for the parameters are reprinted for clarity in Table 4 . The failure probability corresponding with (7) is evaluated directly using the approximate First Order Reliability Method (FORM), as implemented in COMREL $^{21}$. This evaluation does not require repeated sampling of a computationally expensive model. The obtained reliability index $\beta_{f i}=2.67$, corresponding with a failure probability $P_{f, f i}=3.8 \cdot 10^{-3}$, 
considering the definition of the reliability index as listed in Eq. (8) in accordance with EN $1990^{22}$. The design is accepted with respect to the structural fire safety objectives, in accordance with the performance criterion specified in Step 3. The difference in assessed $P_{f, f i}$ relative to the result in 'assessment method 1' results from the rounded input values in the fragility curve, the use of FORM instead of LHS, and the lognormal approximation for the load effect in assessment method 1.

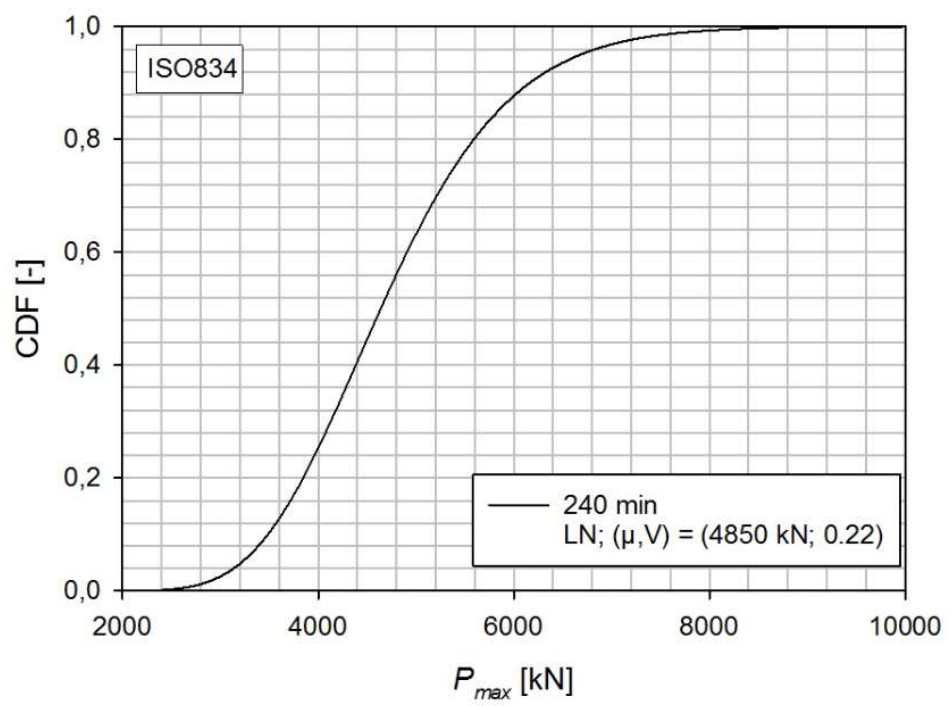

Figure 8. Listed fragility curve for $P_{\max }$, for a concrete column $500 \times 500 \mathrm{~mm}^{2}$, reinforced with $12 \varnothing 20$ rebars, with $f_{y k}=500 \mathrm{MPa}, f_{c k}=30 \mathrm{MPa}$, and a concrete cover $c=42 \mathrm{~mm}$, considering 240 minutes ISO 834 standard fire exposure.

$$
\begin{aligned}
& Z=P_{\text {max }}-K_{E}\left(P_{G}+P_{Q}\right) \\
& P_{f}=\Phi(-\beta)=1-\Phi(\beta)=P_{s}
\end{aligned}
$$

Table 4. Probabilistic models for the variables in Eq. (7)

\begin{tabular}{|l|c|c|c|c|}
\hline Parameter & Distribution & Mean $\boldsymbol{\mu}$ & $\begin{array}{c}\text { Standard } \\
\text { deviation } \boldsymbol{\sigma}\end{array}$ & Reference \\
\hline Permanent load, $P_{G}[\mathrm{kN}]$ & Normal & $P_{G k}$ & $0.1 P_{G k}$ & $\begin{array}{c}\text { Holický and } \\
\text { Sýkora }^{12}\end{array}$ \\
\hline Imposed load, $P_{Q}[\mathrm{kN}]$ & $\begin{array}{c}\text { Gumbel } \\
(5 \text { year reference) }\end{array}$ & $0.2 P_{Q k}$ & $0.22 P_{Q k}$ & $\begin{array}{c}\text { Holický and } \\
\text { Sýkora }^{12}\end{array}$ \\
\hline $\begin{array}{l}\text { Model uncertainty for the load } \\
\text { effect, } K_{E}[-]\end{array}$ & Lognormal & 1.0 & 0.1 & $\begin{array}{c}\text { Holický and } \\
\text { Sýkora }^{12}\end{array}$ \\
\hline $\begin{array}{l}\text { Column load bearing capacity, } \\
P_{\max }[\mathrm{kN}]\end{array}$ & Lognormal & 4850 & 1067 & $\begin{array}{c}\text { isted fragility } \\
\text { curve }\end{array}$ \\
\hline
\end{tabular}

Assessment method 3: semi-probabilistic analysis - specification of global safety factor

For advanced numerical simulations, the achievement of a target reliability through application of safety factors in a single (or limited number) of numerical evaluations is preferred ${ }^{23}$. This is what is commonly referred to as a semi-probabilistic assessment. Considering a general limit state formulation $Z=R-E$ $\geq 0$, the acceptance criterion in a semi-probabilistic assessment is reformulated as Eq. (9), with $R_{d}$ the design value of the resistance $R$, and $E_{d}$ the design value of the load $E$. Furthermore, in accordance with Annex C of EN $1990^{22}$, and under the condition $0.16 \sigma_{R} \leq \sigma_{E} \leq 7.60 \sigma_{R},(10)$ applies, with $\beta$ the reliability index defined in (8).

$R_{d} \geq E_{d}$ 


$$
P\left[R \leq R_{d}\right]=\Phi(-0.8 \beta) \& P\left[E \geq E_{d}\right]=\Phi(-0.7 \beta)
$$

Considering these equations, in the following a global safety factor approach is applied for the concrete column case. Such an approach relies on a single model evaluation to demonstrate achievement of a reliability-based performance criterion. As currently no generally accepted safety factor approach exists for reliability-based structural fire design, background is included below. Although the concept requires further generalization before it can be included in guidance documents, it provides a clear example of how (semi-)probabilistic design methodologies can find their way into design practice.

Starting from the design (acceptance) criterion of Eq. (9), and specifying $R_{d}=R_{k} / \gamma_{R}$, and $E_{d}=\gamma_{E} \cdot E_{k}$, with $\gamma_{R}$ and $\gamma_{E}$ the (global) resistance and load factors, and $R_{k}$ and $E_{k}$ the characteristic resistance and characteristic load (e.g. mean value, or $5 \%$ quantile, as specified), a single global safety factor $\gamma_{0}$ can be defined as in Eq. (11).

$$
\frac{R_{k}}{\gamma_{R}} \geq \gamma_{E} E_{k} \Rightarrow R_{k} \geq \gamma_{R} \gamma_{E} E_{k}=\gamma_{0} E_{k}
$$

In order to apply the above to the pinned column, the limit state of Eq. (1) is rewritten as Eq. (12), taking into account (5), thus defining $R$ as $P_{\max \text {,num }}$ and $E$ as an equivalent total load effect. Since both $P_{E}$ and $K_{R}$ are described by a lognormal distribution (see assessment method 1), $E$ follows a lognormal distribution as well. Also $P_{\max \text {, num }}$ is considered to be described by a lognormal distribution, considering Figure 7. In general cases, the lognormality (or other) of $R$ can be defined in background documents based on literature or industry publications. Taking into account this lognormality, Eqs (13) apply, with $\mu_{\ln X}$ and $\sigma_{\ln X}$ the parameters of a lognormal distribution for variable $X$ as specified in (14).

$$
\begin{aligned}
& Z^{*}=P_{\max , \text { num }}-\frac{P_{E}}{K_{R}}=R-E \geq 0 \\
& P\left[R \leq R_{d}\right]=\Phi\left(\frac{\ln \left(R_{d}\right)-\mu_{\ln R}}{\sigma_{\ln R}}\right) \& P\left[E \geq E_{d}\right]=\Phi\left(-\frac{\ln \left(E_{d}\right)-\mu_{\ln E}}{\sigma_{\ln E}}\right) \\
& \mu_{\ln X}=\ln \left(\mu_{X}\right)-\frac{1}{2} \sigma_{\ln X}^{2} \& \sigma_{\ln X}=\sqrt{\ln \left(1+V_{X}^{2}\right)}
\end{aligned}
$$

Independent from the above, a choice is made to define the design values $R_{d}$ and $E_{d}$ through their mean values (i.e. mean values as characteristic values for Eq. (11), i.e. $R_{d}=\mu_{R} / \gamma_{R}$ and $E_{d}=\gamma_{E}{ }^{*} \mu_{E}$. This specifies Eqs. (13) to:

$$
P\left[R \leq R_{d}\right]=\Phi\left(\frac{-\ln \left(\gamma_{R}\right)+\frac{1}{2} \sigma_{\ln R}^{2}}{\sigma_{\ln R}}\right) \& P\left[E \geq E_{d}\right]=\Phi\left(\frac{-\ln \left(\gamma_{E}\right)-\frac{1}{2} \sigma_{\ln E}^{2}}{\sigma_{\ln E}}\right)
$$

Combining (15) with the Eurocode ("simplified level II") specification of Eqs. (10), results in the (global) resistance and load factors being specified by Eqs. (16) and (17). The equalities in (16) and (17) are obtained by applying $V_{R}=0.15$ (see Table 3) and $V_{E}=0.24$ (i.e. $E$ including the effect of $K_{R}$ ). These right hand equations could be listed in literature or industry guidance documents for wider application.

$$
\gamma_{R}=\exp \left(0.8 \beta_{t} \sigma_{\ln R}+\frac{1}{2} \sigma_{\ln R}^{2}\right)=\exp \left(0.12 \beta_{t}+0.011\right)
$$




$$
\gamma_{E}=\exp \left(0.7 \beta_{t} \sigma_{\ln E}-\frac{1}{2} \sigma_{\ln E}^{2}\right)=\exp \left(0.17 \beta_{t}-0.028\right)
$$

The performance criterion listed in Step 3 specifies a minimum (target) reliability of $5 \cdot 10^{-3}$. Through (8) this corresponds with $\beta_{t, f i}=2.58$, resulting in $\gamma_{R}=1.38$ and $\gamma_{E}=1.49$, and thus a global safety factor $\gamma_{0}=2.05$. Taking into account Eq. (11), and the definition of characteristic values by the means, the acceptance criterion is thus re-specified as:

$$
\mu_{R} \geq \gamma_{0} \mu_{E}=2.05 \cdot 2267 \mathrm{kN}=4647 \mathrm{kN}
$$

The criterion of Eq. (18) states that the column design has a reliability in exceedance of the target of $99.5 \%$ if $\mu_{R}$ (i.e. the mean value of $P_{\max , n u m}$ ) exceeds $4647 \mathrm{kN}$. Confirming this however does not require computationally expensive repeated sampling of the numerical model. The mean value of $P_{\max , \text { num }}$ can be assessed using a first order Taylor approximation whereby the SAFIR model is evaluated using mean values for all input variables. There is also no need to iteratively search for the actual value of $P_{\max , \text { num }}$ associated with this mean input value simulation. It suffices to run the simulation considering an external load of $4647 \mathrm{kN}$ and demonstrate that the 240 minutes ISO 834 threshold is surpassed. Doing this, the SAFIR calculation indicates that stability is maintained beyond 240 minutes of standard fire exposure exceeded (failure time of $290 \mathrm{~min}$ ). Consequently, the design is accepted with respect to the structural fire safety objectives, in accordance with the performance criterion specified in Step 3.

\section{DISCUSSION AND CONCLUSIONS}

The presented study has illustrated three alternative approaches to demonstrate achievement of an absolute safety target for probabilistic structural fire engineering applications. The absolute safety evaluation functions as a conservative proxy for an explicit ALARP evaluation in accordance with PD 7974-7:2019. Tolerability of the design was assumed (in hypothesis taking into account stakeholder communication) based on compliance with prescriptive guidance (and on the prerequisite that the candidate building falls within its scope). The absolute safety target has (in hypothesis) been set through stakeholder consultation. Naturally, the stakeholders can include non-societal safety considerations, such as business continuity, when specifying the absolute safety target. The application of probabilistic approaches allows stakeholders to get a more comprehensive insight in the expected performance of their building in case of fire

While the first demonstrated approach (direct probability evaluation) starts from first principles, its evaluation requires either (i) repeated sampling of the structural model, as in the presented example; or (ii) the use of expert reliability methods. Both constitute a limitation to the further application of probabilistic approaches. The second demonstrated approach relies on the application of fragility curves published (in hypothesis) by academic institutions, industry organizations, or standardization bodies to overcome this drawback. Considering the demonstrated ease-of-use, the presented application is a call for the publication of reference fragility curves for fire-exposed structural elements (and systems). The third demonstrated approach (semi-probabilistic analysis) applies a global safety factor, allowing to demonstrate the achievement of the required reliability with a single model evaluation. The global safety factor relies on a known (here: lognormal) distribution of the column capacity. As the example case demonstrates the straightforward applicability of a global safety factor approach, it functions as a call for establishing standard distribution types for the resistance of structural elements exposed to fire, i.e. a reiteration of the call for the establishment of reference fragility curves.

The further development of probabilistic approaches in (structural) fire engineering through the establishment of reference fragility curves and/or a global safety factor format is considered to allow the designer to focus more on the question of defining a safety approach in communication with the stakeholders, and choosing an appropriate description (i.e. calculation model) for the problem at hand. In an increasingly complex building process, the engineer must thus function as a translator, interpreting 
the structural fire design performance (safety level) and communicating this to the client. It is suggested that a more comprehensive insight in the full range of fire performance of structures can lead to design solutions which more fully fulfil the (implicit) multi-facetted expectations of the stakeholders.

\section{REFERENCES}

${ }^{1}$ Van Coile, R., Hopkin, D., Lange, D., Jomaas, G., \& Bisby, L. (2019). The Need for Hierarchies of Acceptance Criteria for Probabilistic Risk Assessments. Fire Technology (in press).

${ }^{2}$ BSI. (2019). PD 7974-7:2019. Application of fire safety engineering principles to the design of buildings:

Probabilistic risk assessment. British Standards Published Document

${ }^{3}$ Biasoli, F., Mancini, G., Just, M., Curbach, M., Walraven, J., Gmeiner, S., Arrieta, J., Frank, R., Morin, C., Robert, F., Poljansek, M., Kamenarova, B.N., Dimova, S., Pinto Vieira, A. (2014). Eurocode 2: Background \& Applications. Design of Concrete Buildings. Worked examples. Publications Office of the European Union, Luxemburg, Luxemburg. Available online at https://ec.europa.eu/

${ }^{4}$ ISO. (2017). ISO/TR 24679-6:2017. Fire safety engineering - Performance of structures in fire - Part 6:

Example of an eight-storey office building. International Organization for Standardization, Geneva, Switzerland.

${ }^{5}$ Hopkin, D., Spearpoint, M., Arnott, M., Van Coile, R. (2019). Cost-benefit analysis of residential sprinklers Application of a judgement value method. Fire Safety Journal (in press).

${ }^{6}$ ISO. (2019). ISO 24679-1:2019. Fire safety engineering - Performance of structures in fire - Part 1: General. International Organization for Standardization, Geneva, Switzerland.

${ }^{7}$ Gernay, T. (2019). Fire resistance and burnout resistance of reinforced concrete columns. Fire Safety Journal, $104,67-78$.

${ }^{8}$ CEN. (2004). EN 1992-1-2:2004. Eurocode 2: Design of concrete structures - Part 1-2: General rules structural fire design. European Standard.

${ }^{9}$ Franssen, J. M., \& Gernay, T. (2017). Modeling structures in fire with SAFIR ${ }^{\circledR}$ : Theoretical background and capabilities. Journal of Structural Fire Engineering, 8(3), 300-323

${ }^{10}$ JCSS. (2013). Probabilistic Model Code. Joint Committee on Structural Safety. Available online at http://www.jcss.byg.dtu.dk/

${ }^{11}$ Qureshi, R., Ni, S., Elhami Khorasani, N., Van Coile, R., Hopkin, D., Gernay, T. (2019). Probabilistic models for temperature dependent strength of steel and concrete. Under review.

${ }^{12}$ Holický, M., Sýkora, M. (2010), Stochastic models in analysis of structural reliability. Stochastic Models in

Reliability Engineering, Life Sciences and Operation Management. Beer Sheva. pp. 428-439.

${ }^{13}$ Elhami Khorasani, N., Gardoni, P., \& Garlock, M. (2015). Probabilistic fire analysis: material models and evaluation of steel structural members. Journal of Structural Engineering, 141(12), 04015050.

${ }^{14}$ Gernay, T., Van Coile, R., Elhami Khorasani, N., \& Hopkin, D. (2019). Efficient uncertainty quantification method applied to structural fire engineering computations. Engineering Structures, 183, 1-17.

${ }^{15}$ Ditlevsen, O., Madsen, H.O. (2007). Structural Reliability Methods (edition 2.3.7). Available online at http://od-website.dk/books/OD-HOM-StrucRelMeth-Ed2.3.7.pdf

${ }^{16}$ Olsson, A. M., \& Sandberg, G. E. (2002). Latin hypercube sampling for stochastic finite element analysis. Journal of Engineering Mechanics, 128(1), 121-125

${ }^{17}$ Van Coile, R., Balomenos, G. P., Pandey, M. D., \& Caspeele, R. (2017). An unbiased method for probabilistic fire safety engineering, requiring a limited number of model evaluations. Fire Technology, 53(5), $1705-1744$

${ }^{18}$ Gernay, T., Khorasani, N.E., Garlock, M. (2019). Fire Fragility Functions for Steel Frame Buildings: Sensitivity Analysis and Reliability Framework. Fire Technol. https://doi.org/10.1007/s10694-018-0764-5 (in press)

${ }^{19}$ Rush, D., \& Lange, D. (2017). Towards a fragility assessment of a concrete column exposed to a real fire-

Tisova Fire Test. Engineering Structures, 150, 537-549.

${ }^{20}$ Hopkin, D., Van Coile, R., \& Fu, I. (2018). Developing fragility curves and estimating failure probabilities for protected steel structural elements subject to fully developed fires. In 10th International Conference on

Structures in Fire.

${ }^{21}$ RCP Consult (2018). COMREL user's manual.

${ }^{22}$ CEN. (2002). EN 1990:2002. Eurocode 0: Basis of structural design. European Standard.

${ }^{23}$ Cervenka, V. (2008). Global safety format for nonlinear calculation of reinforced concrete. Beton-und Stahlbetonbau, 103(S1), 37-42.

Changes relative to the original published manuscript: (i) Figure 6 corrected; (ii) formulation (18) clarified. 